\title{
Industry 4.0 and New Paradigms in the Field of Metal Forming
}

\author{
Mladomir Milutinović*, Mijodrag Milošević, Jovica llić, Dejan Movrin, Milija Kraišnik, Saša Ranđelović, Dejan Lukić
}

\begin{abstract}
Over the last few year, the metalworking sector has been undergoing rapid and radical transformations driven by global competition and the revision of the production focus that is being moved from mass customization to mass individualization. A results of this is introduction of new manufacturing strategies such as Industry 4.0, a concept that combines cyber-physical systems and promote communication and connectivity. Therefore, this concept changes not only the face of the manufacturing systems but also causes transformation of existing business models and the society as a whole. This paper deals with the recent trends and paradigms in the field of metal forming, resulting from the concept of Industry 4.0 and the modern market challenges. The maim attention is paid on the flexibility of manufacturing systems and recent developments in design of smart forming tools.
\end{abstract}

Keywords: flexibility; Industry 4.0; metal forming; smart tools

\section{INTRODUCTION}

The Industry 4.0 (I4.0) represents the framework of a new industrial revolution that relies on digitalization and networking as well as the fusion of the cyber and physical worlds [1]. This concept is based on the intelligent connection of mechanical, electrical and software engineering, which contributes to the development of new technologies and business models, as well as new approaches to work and thinking. It was first presented at the Hanover Messe (2011) as a strategic project of the German government, companies and science with goal to help German manufacturers to become more competitive in global markets through better use of information technology and the Internet [1]. Shortly afterwards, the potential of I4.0 was recognized by others manufactures worldwide and it has quickly become a global phenomenon. I4.0 integrates dozens of technologies, some of which have evolved decades ago but new technologies are being developed on a daily basis and included in this concept. A results of this is a series of innovations that leap forward traditional factories to a fully connected and flexible manufacturing system. In essence, Industry 4.0 creates what has been called a smart factory.

Implementation of I 4.0 is a complex process that causes significant costs, requires time and knowledge, and has its own operating costs. However, each company and technology sector must have its own view of implementation - there is no "exact level" of implementation that can be recommended. In this paper, some of the challenges that companies from metal forming industry are faced with in the implementation of the I 4.0 concept as well as recent advances and future trends in metal forming sector are discussed.

\section{BASIC TECHNOLOGIES OF INDUSTRY 4.0}

As mentioned above, Industry 4.0 is a very complex concept that utilizes innovative, cutting edge technologies integrated into a highly sophisticated manufacturing system (Fig.1). There are several key technologies of I4.0 [3]: CyberPhysical Systems, Industrial Internet of Things, Cloud Manufacturing, Big Data, Machine-to-Machine communication (M2M), Augmented \& Virtual Reality, Digital Twins, Smart Maintenance, Energy Efficiency Monitoring, Reconfigurable, Connected \& Smart Factory etc.

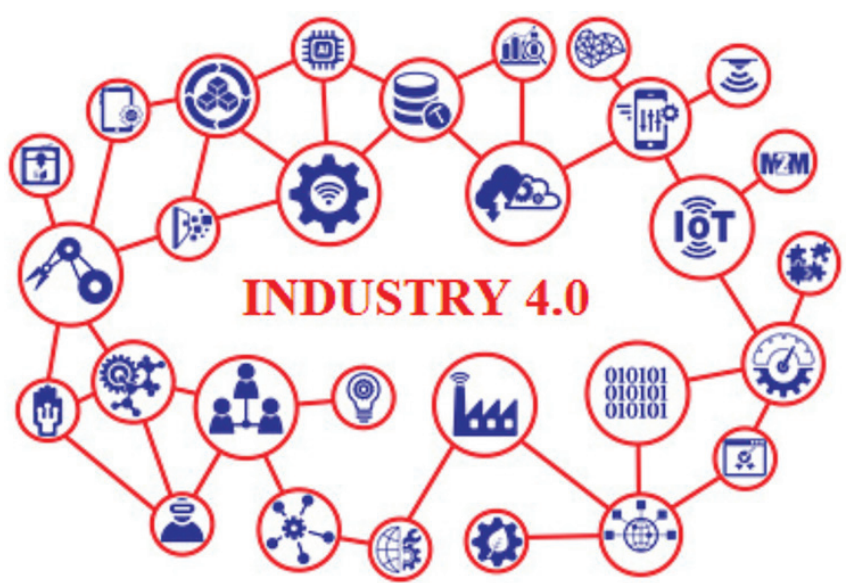

Figure 1 Key technologies of Industry 4.0 and their integration

In addition to integration, communication and information exchange are crucial issues for the implementation of I4.0 technologies [4]. Namely, by adding sensors, actuators and other types of intelligent components to physical objects and devices we create integrated systems, but only if enable network communication between such systems they will be upgraded to cyber-physical systems intelligent, networked systems with built-in sensors, actuators and processors that interact with the physical world (including humans as users) and support real-time operations. They represent the integration of local "intelligence" and communication capacities, and thanks to the built-in microcontroller these systems are "smart enough" to be able to make independent decisions. However, although their decisions are autonomous and decentralized, they are still in line with the process plan defined at higher levels of decisionmaking.

When assign IP addresses to cyber-physical systems, we get the Internet of Things (IoT). In this way the devices are 
able to exchange data with applications, operators and / or other connected devices. IoT enables objects to be located and remotely controlled via the existing network infrastructure as well as to change and adapt the "intelligence" of the objects remotely. Industrial Internet of Things (IIoT) refers to interconnected sensors, instruments, as well as other industrial devices and objects networked together with industrial applications including power management systems.

Cloud technology is a set of networked computing resources that provide IT infrastructure and services, including operating systems, applications, internal and external data storage space. Appropriate services are accessed over networks without the need to install software on the user's computer. The provision and use of IT services is enabled through different types of interface, protocols and web browsers. By switching to cloud technology, significant savings are achieved in terms of hardware, labor and energy. In this way, companies can reduce annual operating IT costs by over $80 \%$. Some of the well-known cloud solutions used in the industry are: Dashboards (FESTO), MindSphere (SIEMENS) and Factory Cloud (ROCKWELL).

In industrial plants and processes, real-time data of large volume and various formats are generated at high speed. Big data technology enables continuous collection of information from various sources with the capacity of search and analysis in order to optimize production processes and workflows. The data obtained from the sensors are analyzed using algorithms for the so-called data mining. These algorithms are based on intelligent mathematical and statistical models and machine learning methods. The goal is to find behavioral patterns by revealing hidden connections between collected data.

M2M communication refers automated data exchange between machines and devices. To enable this, the machines have to be networked and ready to exchange data. In addition, an adequate standard (protocol) for communication is required. This allows machines to gain information about current production processes and, if necessary, to make corrections/changes in a particular operation or production flow. In this way manufacturing systems become reconfigurable, which is one of the most important features of Industry 4.0. The goal is personalized of production where, within mass production, individual corrections are automatically made in accordance with customer requirements.

Augmented reality is a technology that allows superimposition of the visible (real) world and the digital content, which is achieved through the use of digital visual elements or other sensory stimuli items. This is an auxiliary system used in logistics, maintenance, assembly, etc. (Assisted Operator). A distinction should be made in relation to the concept of virtual reality, where the real world is completely replaced by virtual.

Digital twin is a digital clone of a process, product, or service. It is a virtual image (virtual prototype), ie a digital replica of a real product, physical object, process or system. The concept of digital twin is defined as a digital record of components' and system behavior during the real operations that help optimization i.e., improvement and enhancement of system performance. It is, therefore, a link between a real object and its digital display that continuously utilizes data from the sensors located in a physical object. Real object data are used to enhance digital copy in real time. The digital display is then used for visualization, modeling, analysis, simulation and additional planning, as well as for various corrections and interventions on a real object.

Smart maintenance is based on predictive maintenance that includes continuous or periodic sensory-based monitoring of physical changes of machine conditions and process state (Condition Monitoring), as well as analysis of data obtained using machine learning methods or artificial intelligence. Accordingly, production downtime is avoid or minimized in a timely manner. The basic monitoring techniques are: analysis and diagnostics of vibrations, acoustic emission, analysis of thermal behavior, infrared thermography, ultrasonic testing, analysis of energy consumption, analysis of abrasives and particles, analysis of coolants and lubricants, etc.

Energy efficiency monitoring includes real-time monitoring of energy consumption and comparison with periodic archived data. Energy efficiency aims to use less energy for the same task. Focus is also placed on the use of renewable energy sources.

The central objective of I4.0 is a smart factory that represents an intelligent production environment in which production resources and logistics systems are organized mainly without human assistance. Employees, who are responsible for supervising and controlling of production lines, can fulfill these tasks remotely. The control realized from remote consoles is extensive and includes many functions, from output-level control to repair and maintenance.

However, it should be said that such highly automated environments have certain limitations. Personalization in production is becoming more demanding and very common regarding sophisticated customer expectations in modern society. This is where the concept of Industry 5.0 is applied, as the next step in the evolution of production. Under this new paradigm humans have been reintroduced into the process increasing their collaboration with robots and intelligent machines within factory plants. The role of humans in I4.0 is based on decision making, monitoring and preventive maintenance, while in I5.0 there is an active collaboration between humans and robots. Human intuition, reasoning and, critical thinking are resources that robots do not possess yet. In another words, Industry 5.0 should provide the best of both worlds: the benefits of robotics combined with advanced human cognitive abilities. In such an environment, product lines can become even "smarter", with people being able to participate more in customizing products.

\section{RECENT AND FUTURE TRENDS IN METAL FORMING}

Metal forming is one of the oldest way of processing metal material, which, according to Groche et al [5], has played a significant role in both society and manufacturing 
development. Several features characterize today's metal forming industry. First one is high degree of diversity - there is a variety of manufacturing procedures, materials, products and, machine and tool systems. Heterogeneity is also present in organizational structures and company sizes [6]. Another characteristic feature of this industry is focus on mass production. It results from high manufacturing costs (energy consumption, tool and machine costs) and low flexibility level since in most forming processes geometry of die/punch is fixed i.e., exclusively depends on the geometry of workpiece. The process conditions, in general, are nonstationary. It includes a change in tribological conditions, material properties, elastic response of the tool-machine system etc., and thus, application of the adaptive process control is quite limited. Due to all this, the implementation of the Industry 4.0 concept in the field of metal forming is a very challenging issue that requires close cooperation between researchers, industry and customers.

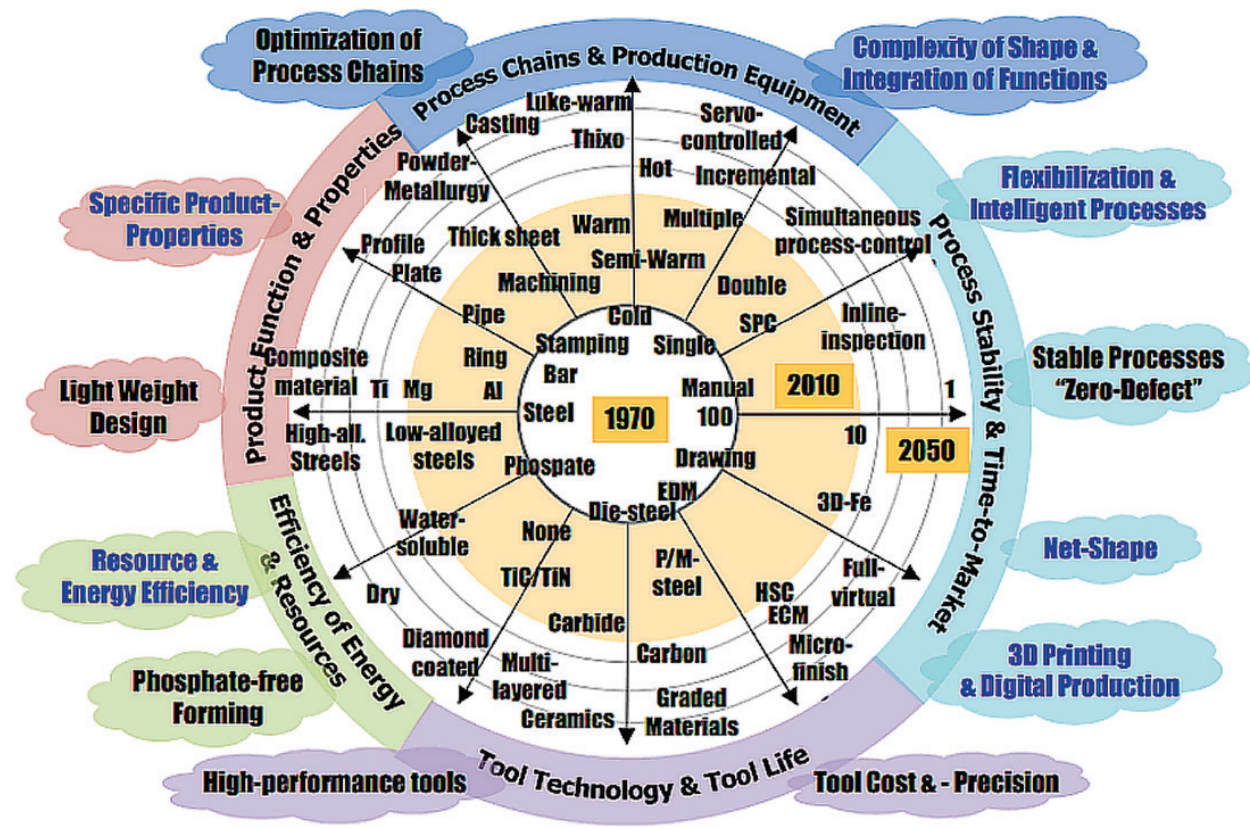

Figure 2 Recent and future trends in metal forming [7]

A summary of recent and future trends in the field of metal forming made by a group of experts within the International Cold Forging Group (ICFG) is given in Fig. 2. As can been seen, one of the major trend is aimed at increase of manufacturing flexibility and development of intelligent production systems. i.e., introduction of smart tools and machine, which is in harmony with the concept of I. 4.0.

\section{FLEXIBILITY IN METAL FORMING}

In recent years, the focus of industrial production has shifted from mass customization to mass individualization as result of increased competition in the global market as well as rapid changes in customers' habits and requirements [8]. In this respect, the development of highly flexible manufacturing procedures and systems is crucial.

As mentioned above, the flexibility of metal forming systems is generally poor, especially in case of conventional forming processes such as forging, extrusion, deep drawing, forming etc., which are carried out as a single-stroke process with specialized (dedicated) punch and die. To overcome this, several innovative forming processes based on incremental manner of deformation have been developed allowing for an easy modification of the product geometry. Using incremental forming approach a wide range of products can be obtained without any or with minimal modifications in the manufacturing system and thus, the economical output can be achieved even in case of individual and or small-batch production. Incremental forming is particularly convenient for manufacturing over-sized parts like shafts for power plants and large ships, space rocket bodies as well as highly personalized medical components. This technique also offers the possibility to produce complex shapes that were previously difficult to produce through conventional forming processes.

Incremental forming refers to processes that rely on a progression of localized deformation. It means that at any time only a small portion of the part is actually being formed while the desired shape is obtained by a series of small incremental deformations by applying localized pressure with a forming tool. Depending on the tool-machine system the zone of local plastic deformation is moving (over the entire volume) continuously or discontinuously.

In addition to economic advantages incremental forming also provides several technical benefits. A result of incremental manner of deformation is significant reduction of contact pressure and forming load compared to the conventional forming procedures. This enables use of smallsized machines of light bodies and low operating costs. Another benefit of low forming loads is a reduction of tool wear, which have a positive effect on both tool life and process stability. Further, due to gradual forming, this 
technique is suitable for processing materials of limited (low) formability such are high strength steels, titanium and titanium alloys, magnesium etc. Incremental forming processes are commonly performed at room temperature (cold forming) employing small, simple and cheap tool while the subsequent machining is reduced to a minimum since parts with a high degree of finalization are generally obtained (near-net shape and net shape parts).

Among the forthcoming flexible forming techniques, one that has attracted a lot of attention is Single Point Incremental Forming (SPIF) [9], which scheme is present in Fig. 3. It is also known as "dieless" technology since forming process is carried out using a universal tool - no dedicated die, which trajectory is programmed in advance and controlled by a CNC machine. In other words, all data regarding the geometry derive from the path of the forming tool. Therefore, it could be said that there is no limit in term of part geometry that can be obtained by the SPIF. Recently, multi-axis robots are increasingly used in the SPIF operations to further increase flexibility and productivity of the process. The SPIF was basically developed to serve the needs for prototyping and small-batch production in automotive and aerospace industry, but the application domain has been expanded over time [10].

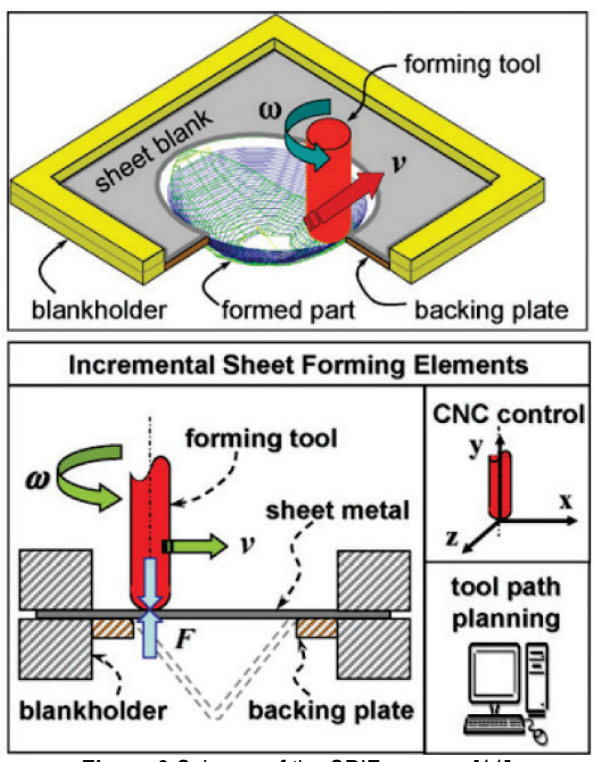

Figure 3 Scheme of the SPIF process [11]

The SPIF is often combined with conventional sheet forming methods (deep drawing, stretching) as well as Additive Manufacturing and Rapid Tooling (RT) technologies with goal to shorten the processing time, which is generally long in the SPIF. It is illustrated in Fig. 4 where deep drawing tooling produced by an AM/RT technique (Laminated Object Manufacturing - LOM) is employed to obtain a preform for the SPIF process. The main feature of this concept is the short time for design and manufacture of the punch and die. The processing time is also considerably reduces since the SPIF process (time consuming) is applied only in finishing stage to form the final shape of workpiece bottom.

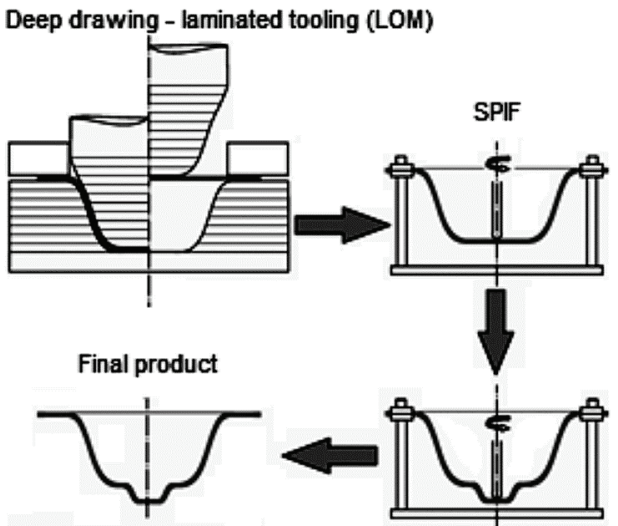

Figure 4 Integration of conventional and incremental forming [12]

The combination of stretch forming and Asymmetric Incremental Sheet Forming (AISF) is shown in Fig. 5. This hybrid process allows noticeable reduction of processing time and material thinning, which are main drawback of the AISF.

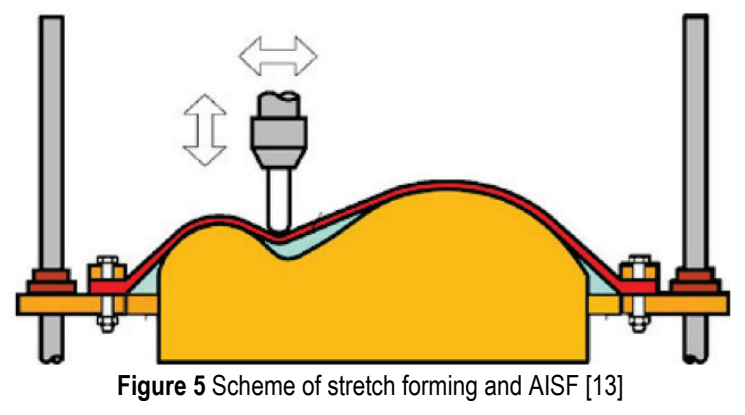

Digitized-die forming (DDF) is a new flexible manufacturing technology that employs specialized machines and tools to convert sheet metal plate into custom three-dimensional shapes. This technology known also as reconfigurable multipoint forming (RMF) is based on the concept of a die continuous surface discrete approximation. The core element of the DDF system is a cluster tool consisting of a pair of matrices of punches that are controlled by computer. The working surface of digitalized die is created by changing the height (vertical position) of each punch (Fig. 6). The DDF system allows for control of part geometry and compensation of the shape errors caused by material elastic springback and other process uncertainties, thus ensuring high accuracy of sheet part.

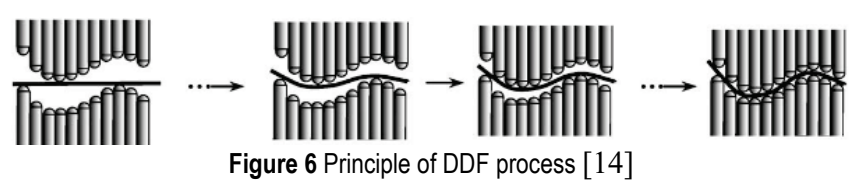

Another strategy to increase the flexibility level in sheet metal forming processes is based on substitution of the conventional die or punch with flexible media, such as elastomers (rubber forming processes), liquids (hydroforming processes) or gases [21]. Metal forming with help of an incompressible fluid or hydroforming was first introduced in Japan in the early 1960s, but only with recent advances in 
the tool-machine systems it is now possible to use commercially this technology in the production of metal components. Hydroforming processes offer several technical and economic advances. This technique allows processing of hard to deform materials, reduction in the number of forming stages/operations (complex shapes can be made in one step), reduction of friction and material utilization, tool cost reduction, set-up time reduction. Other advantages are increase of the material formability, more uniform thickness distribution, lower level of residual stresses, and better surface quality compared to part obtained using traditional forming process. Finally, part produced by hydroforming exhibit optimal mass to strength ratio. The scheme of hydroforming process is given in Fig. 7.

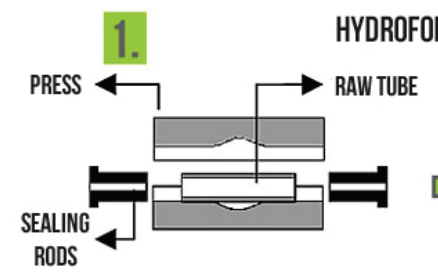

HYDROFORMING
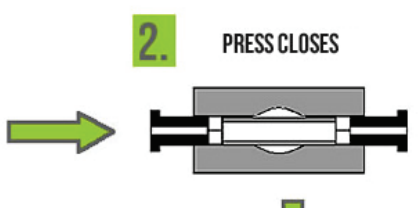

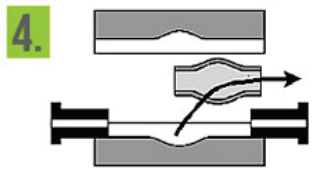

HIGH PRESSURE FLUID IS RELEASED

AND THE HYDROFORMED TUBE IS REMOVED.

Figure 7 Tube hydroforming [22]

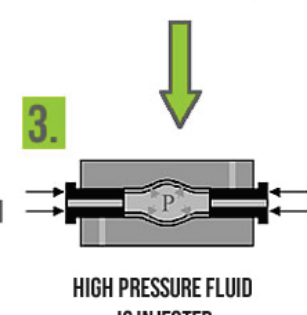

ISINJECTED
Hydroforming is predominately used in automotive industry (Fig. 8), but this technique is also suitable for prototyping and small-scale production of parts for the aerospace industry.

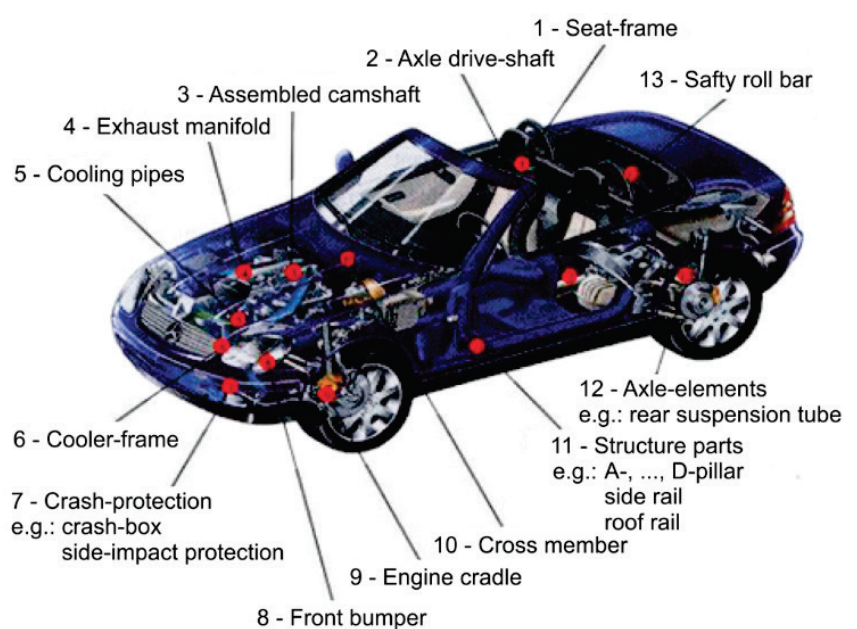

Figure 8 Examples of the automotive parts manufactured by tube hydroforming process [23]

\section{SMART FORMING TOOLS}

In a conventional metal forming process, the tool (punch and die) has a dominant influence on the part accuracy since it is a "negative" of the part to be manufactured (tool contain the contour of the desired part). Therefore, any deviation of the punch/die geometry from the desired due to design/manufacturing inaccuracies leads to the systematic errors (fixed, permanent) in workpiece geometry. In addition, the nominal dimensions of tools are continuously changing in exploitation due to tool elastic and plastic deformations, thermal expansion, wear occurrence etc., resulting in additional dimensional errors, which are permanent but not consistent in the amount. Further, the fluctuation in mechanical properties of input material or the load oscillations of crank press produce random errors. In this regards, it can be said that the final geometry of workpiece depends more of the above phenomena than on the nominal dimensions of tool. For this reason traditional passive metal forming tools are increasingly replaced by innovative/smart tools that are capable to collect valuable information for monitoring and control of metal forming processes [15]. This allows to take appropriate measures and corrective actions in a timely manner (active/dynamic compensation) so that errors and possible failures can be minimized or completely eliminated and the concept of zero defect manufacturing attained.

Today, with high levels of digitization and the possibility of almost unlimited digital networking, the future of tooling is smart one - data collection, exchange, analysis and adaptability are key features of tools in Industry 4.0 [16]. Classification of innovative, smart forming toolstructures/systems according criterion of tool "intelligence" level is shown in Fig. 9. All listed tool structures are advanced concepts but only intelligent tools with active, "inprocess" control capability are suitable for integration in cyber-physical systems within Industry 4.0. To achieve this goal, these tools are equipped with intelligent components such as sensors, actuators and control systems to enable communication with other elements of the manufacturing system and to allow for the receiving and processing of measured/controlled data and information from of the manufacturing environment [16]. The structures of intelligent forming tools are depicted in Fig. 10.

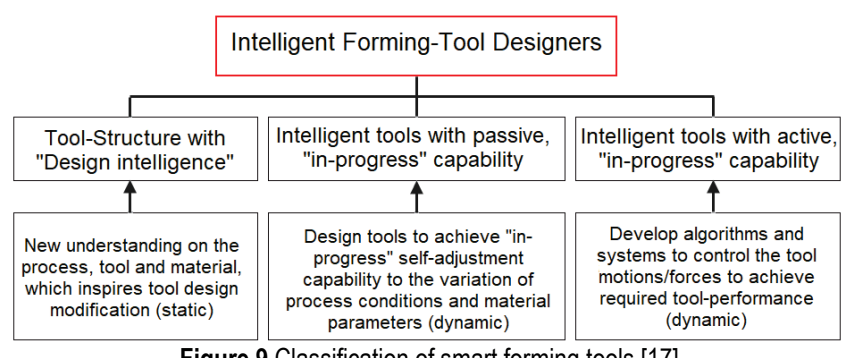

Smart forming tools include various types of sensors integrated into the tool at relevant location to convert process information into electrical signals, which are then amplified and processed/estimated by monitoring system - a set of data regarding the discrepancy between the actual and set values is obtained. Successful implementation of sensor strategies is based on successful detection and measurement of variables 
that correlate with the accuracy/quality of the part for a given forming process [15]. A large number of contact and noncontact sensors are used in metal forming for measuring displacement, surface properties, force, temperature, microstructure, defects, residual stresses and materials properties process [18]. For example, in forging processes information about the part and die temperature and its distribution is crucial issue not only for the part quality but also for heating strategy and die life. Thermocouples are mostly used to measure the forging die temperature. However, the thermocouple can usually only be installed with a minimum distance from the die surface and thus, the measured temperature is only an approximation of the real temperature. More accurate and consistent temperature measurement throughout forging process is achieved by employing optical pyrometers, infrared temperature sensors or thermal imaging cameras. Typically, optical pyrometers measure temperature to an accuracy of 1 to $2 \%$ of the fullscale range, which can reach $3300{ }^{\circ} \mathrm{C}$ [19].
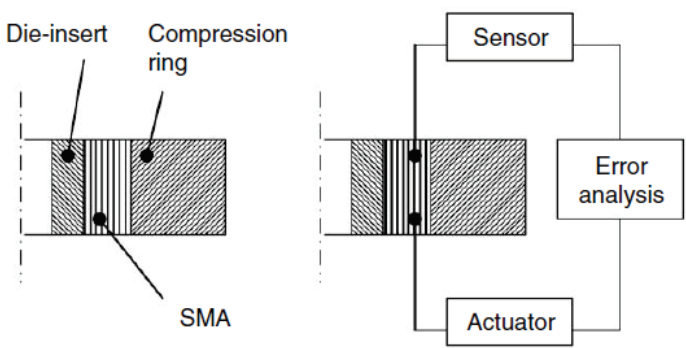

Figure 10 Structure of smart die structure with an SMA (smart memory alloy) for passive compensation (left) and die structure with an SMA for active control (right) [17]

Actuators are devices that converts electrical or physical signals/inputs into mechanical outputs, such as displacement, force, angle, or torque. Actuators used in forming processes enable the control/corrective actions to be carried out i.e., an update of the forming system in accordance with the deviation detected using sensors to obtain product with desired properties. Currently, in the field of metal forming, actuators are predominately employed to perform mechanical work (displacement and force) or to apply heat [18]. The requirements that actuators must meet in order to be efficiently employed in metal forming processes are high dynamic response, high force and high precision.

In metal forming processes, as with many other engineering systems, there are two control approaches applied: open loop and closed loop systems. Systems with closed loop control have the ability to control the system by monitoring the current output and correcting any deviations from the projected output values. This type of control requires an integrated measuring system. A typical closed loop control scheme of an advanced deep drawing tool with integrated process and product sensors is shown in Fig. 11. In most cases, deep drawing control strategies are being developed to enable a controlled flow of sheet blank by adjusting the blank holder force.

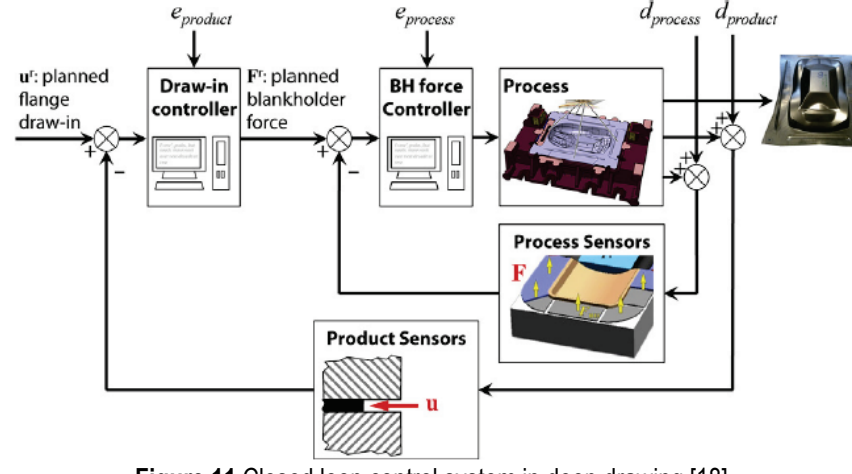

Figure 11 Closed loop control system in deep drawing [18]

Fig. 12 shows several measurement methods for control of bending angle and measuring material elastic springback, which can be integrated into a closed loop control system.

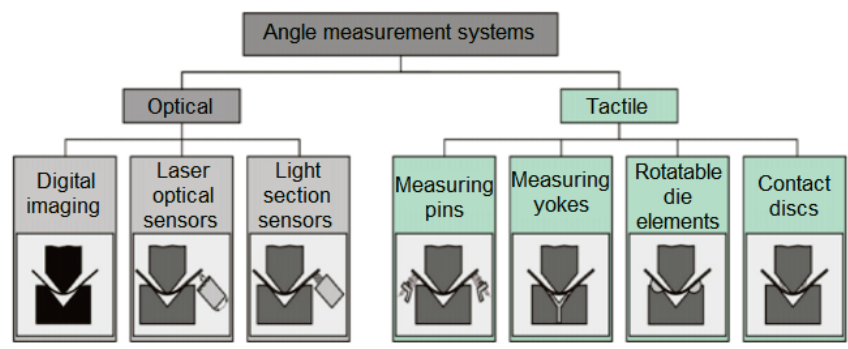

Figure 12 Different bending angle measurement methods [18]

One of the major goals in developing advanced metal forming processes is to reduce uncertainties caused by the variations in input material properties. In this objective, several material control systems based on different strategies were proposed such as the concept of data flow of material property control function intended for feed-forward control of sheet metal forming processes (Fig. 13) using on-line indentation test [20].

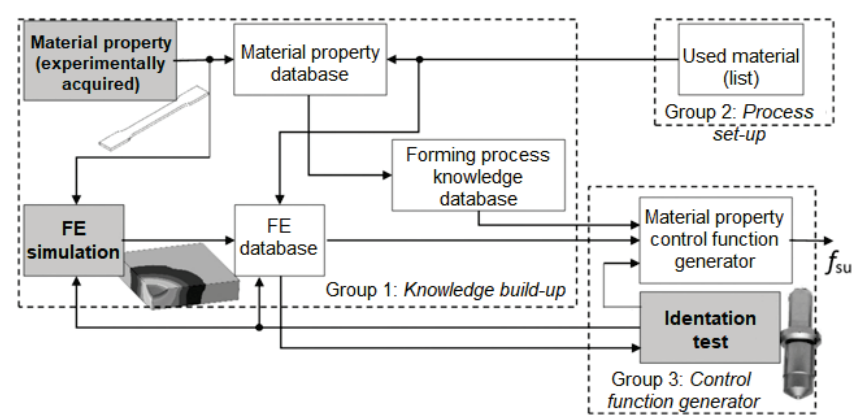

Figure 13 Data flow for material properties control in sheet metal forming [19]

\section{CONCLUSION}

Key strategy of Industry 4.0 is the creation of new innovation for smart systems such as smart forming tools, which is one of the most important components in metal forming production lines. An advanced smart forming tool is required to be equipped with sensors to measure and monitor various parameters of a forming process as well as actuators to fulfill control actions. In addition, such tool should be highly flexible in order to reduce production cost and 
increase process efficiency. It is expected that further development of information and communication technologies, non-conventional manufacturing technologies, computer technologies, measuring techniques etc. will significantly enhance the performance (flexibility, "intelligence", tool life, ...) of metal forming tools in line with the Industry 4.0.

\section{Notice}

The paper will be presented at MOTSP $2021-12^{\text {th }}$ International Conference Management of Technology - Step to Sustainable Production, which will take place in Poreč/Porenzo, Istria (Croatia), on September 8-10, 2021. The paper will not be published anywhere else.

\section{REFERENCES}

[1] Drath, R. \& Horch, A. (2014). Industrie 4.0: Hit or Hype? IEEE Industrial Electronics Magazine, 8, 56-58. https://doi.org/10.1109/MIE.2014.2312079

[2] Pfeiffer, S. (2017). The Vision of "Industrie 4.0" in the Making - a Case of Future Told, Tamed, and Traded. Nanoethics, 11, 107-121. https://doi.org/10.1007/s11569-016-0280-3

[3] Milošević, M., Lukić, D., Đurđev, M., \& Vukman, J. (2019). Digital Transformation of Manufacturing towards Industry 4.0 Concept. The international conference of the Carpathian euroregion specialists in industrial systems CEurSIS 2019, $12^{\text {th }}$ Edition, Baia Mare, Romania. https://doi.org/10.1088/1757-899X/749/1/012019

[4] Qin, J., Liu Y., \& Grosvenor, R. (2016). A Categorical Framework of Manufacturing for Industry 4.0 and Beyond. Procedia CIRP, 52, 173-178. https://doi.org/10.1016/j.procir.2016.08.005

[5] Groche, P., Fittshe, D., Tekkaya, E. A., Allwood, J. M., Hirt, G., \& Neugebauer, R. (2007). Incremental Bulk Forming, Annals of CIRP, 55(2), p. 636. https://doi.org/10.1016/j.cirp.2007.10.006

[6] Ralph, B. J. \& Stockinger, M. (2020). Digitalization and digital transformation in metal forming: key technologies, challenges and current developments of industry 4.0 applications. In XXXIX. Verformungskundliches Kolloquium: Zauchensee 2020, Montanuniversität Leoben, Lehrstuhl für Umformtechnik, 13-23.

[7] Mega-trends and Future of Metal Forming (2012). Meeting note of Working Group of ICFG 2012.

[8] Yang, D. Y., Bambach, M., Cao, J., Duflou, J. R., Groche, P., Kuboki, T., Sterzing, A., Tekkaya, A. E., \& Lee, C. W. (2018). Flexibility in metal forming. CIRP Annals, 67(2), 743-765. https://doi.org/10.1016/j.cirp.2018.05.004

[9] Behera, A. K., de Sousa R. A., Ingarao, G., \& Oleksik, V. (2017). Single point incremental forming: An assessment of the progress and technology trends from 2005 to 2015. Journal of Manufacturing Processes, 27, 37-62. https://doi.org/10.1016/j.jmapro.2017.03.014

[10] Milutinović, M., Lendjel, R., Baloš, S., Labus Zlatanović, D., Sevšek, L., \& Pepelnjak, T. (2021). Characterisation of geometrical and physical properties of a stainless steel denture framework manufactured by single-point incremental forming. Journal of Materials Research and Technology, 10, 605-623. https://doi.org/10.1016/j.jmrt.2020.12.014
[11] Jeswiet, J., Geiger, M., Engel, U., Kleiner, M., Schikorra, M., Duflou, J., Neugebauer, R., Bariani, P., \& Bruschi, S. (2008). Metal forming progress since 2000. CIRP Journal of Manufacturing Science and Technology, 1(1), 2-17. https://doi.org/10.1016/j.cirpj.2008.06.005

[12] Kuzman, K., Pepelnjak, T., \& Petek, A. (2008). Comments on technology selection for small batch sheet metal forming operations. Proceedings of the $32^{\text {nd }}$ Conference on production engineering with foreign participants, Novi Sad, Serbia, 2008, 129-133.

[13] Araghi, B. T., Manco, G. L., Bambach, M., \& Hirt, G. (2009). Investigation into a New Hybrid Forming Process: Incremental Sheet Forming Combined with Stretch Forming. CIRP AnnalsManufacturing Technology, 58, 225-228. https://doi.org/10.1016/j.cirp.2009.03.101

[14] Li, M.-Z., Cai, Z.-Y., \& Liu, C.-G. (2007). Flexible manufacturing of sheet metal parts based on digitized-die. Robotics and Computer Integrated Manufacturing, 23(1), 107115. https://doi.org/10.1016/j.rcim.2005.09.005

[15] Cao, J., Brinksmeier, E., Fu, M., Gao, R.-X., Liang, B., Merklein, M., Schmidt, M., \& Yanagimoto, J. (2019). Manufacturing of advanced smart tooling for metal forming. CIRP Annals - Manufacturing Technology, 68(2), 605-628. https://doi.org/10.1016/j.jmrt.2020.12.014

[16] https://www.etmm-online.com/smart-tooling-smart tools-andsmart-services-a-583918/ (Accessed: 26.04.2021).

[17] Qin, Y. (2006). Forming-tool design innovation and intelligent tool-structure/system concepts. International Journal of Machine Tools and Manufacture, 46(11), 1253-1260. https://doi.org/10.1016/j.ijmachtools.2006.01.013

[18] Allwood, J. M., Duncan, S. R., Cao, J., Groche, P., Hirt, G., Kinsey, B., \& Tekkaya, A. E. (2016). Closed-loop control of product properties in metal forming. CIRP Annals, 65(2), 573596. https://doi.org/10.1016/j.cirp.2016.06.002

[19] https://www.processsensors.com/industries/steel/steelforming-temperature (Accessed: 26.04.2021).

[20] Satošek, R., Valeš, M., \& Pepelnjak, T. (2019). Study of Influential Parameters of the Sphere Indentation Used for the Control Function of Material Properties in Forming Operations. Strojniški vestnik, 65(10), 585-598. https://doi.org/10.5545/sv-jme.2019.6312

[21] Alberti, N. \& Micari, F. (2002). Analysis of Some Innovative and Flexible Sheet Forming Processes. Kulianic, E. (eds) AMST'02 Advanced Manufacturing Systems and Technology. International Centre for Mechanical Sciences (Courses and Lectures), vol 437. Springer, Vienna. https://doi.org/10.1007/978-3-7091-2555-7

[22] https://www.bike-advisor.com/what-is-hydroforming/. (Accessed: 26.04.2021).

[23] https://www.totalmateria.com/page.aspx?ID=CheckArticle\& site $=\mathrm{kts} \& \mathrm{LN}=\mathrm{SH} \& \mathrm{NM}=344$. (Accessed: 26.04 .2021 ).

\author{
Authors' contacts: \\ Mladomir Milutinović, Associate Professor PhD \\ (Corresponding author) \\ University of Novi Sad, Faculty of Technical Science, \\ Trg Dositeja Obradovića 6, 21000 Novi Sad, Serbia \\ mladomil@uns.ac.rs \\ Mijodrag Milošević, Associate Professor PhD \\ University of Novi Sad, Faculty of Technical Science, \\ Trg Dositeja Obradovića 6, 21000 Novi Sad, Serbia \\ mido@uns.ac.rs
}


Jovica llić, MSc, Senior Teaching Assistant

University of Banja Luka, Faculty of Mechanical Engineering,

Bulevar vojvode Stepe Stepanovica 71,

78000 Banja Luka, Republic of Srpska, Bosnia and Herzegovina

jovica.lic@mf.unibl.org

Dejan Movrin, Assistant Professor, PhD

University of Novi Sad, Faculty of Technical Sciences,

Trg Dositeja Obradovića 6, 21000 Novi Sad, Serbia

movrin@uns.ac.rs

Milija Kraišnik, Associate Professor PhD

University of East Sarajevo,

Faculty of Mechanical Engineering East Sarajevo,

Vuka Karadzica 30, 71126 Lukavica, East Sarajevo,

Republic of Srpska, Bosnia and Herzegovina

milija.kraisnik@ues.rs.ba

Saša Ranđelović, Full Professor PhD

University of Nišs, Faculty of Mechanical Engineering,

Aleksandra Medvedeva 14, 18000 Niš, Serbia

sassa@masfak.ni.ac.rs

Dejan Lukić, Associate Professor PhD

University of Novi Sad, Faculty of Technical Sciences,

Trg Dositeja Obradovića 6, 21000 Novi Sad, Serbia

lukicd@uns.ac.rs 